\title{
Repositioning liothyronine for cancer immunotherapy by blocking the interaction of immune checkpoint TIGIT/PVR
}

\author{
Xiuman Zhou', Jiangfeng Du², Hongfei Wang ${ }^{2}$, Chunxia Chen², Ling Jiao², Xiangrui Cheng ${ }^{2}$, Xiaowen Zhou²,
} Shaomeng Chen ${ }^{3}$, Shanshan Gou', Wenshan Zhao ${ }^{2}$, Wenjie Zhai ${ }^{2}$, Junhui Chen ${ }^{1 * \dagger}$ and Yanfeng Gao ${ }^{1,3^{*+}}$ (D)

\begin{abstract}
Background: Inhibitors targeting immune checkpoint were proved effective in cancer immunotherapy, such as PD1/PD-L1 blockade. The novel immune checkpoint TIGIT/PVR plays critical roles in suppressing the anti-tumor effects of $\mathrm{CD}^{+} \mathrm{T}$ and NK cells, and dual blockade of TIGIT/PVR and PD-1/PD-L1 by antibody can elicit synergistic effects in tumor models and clinical trials. However, small molecules for TIGIT/PVR blockade have not been investigated.

Methods: The expression of PVR in tumors were analyzed by using TCGA, Oncomine and GEO database, and in cancer cell lines examined by flow cytometry. Natural product compounds were docked to PVR for virtual screening by using the software Molecular Operating Environment (MOE). Candidate compounds were further tested by biolayer interferometry-based binding assay, microscale thermophoresis assay and cell based blocking assay. The in vitro activity of the candidate compound was determined by MTT, peripheral blood mononuclear cells (PBMCs) activation assay and coculture assay. The anti-tumor effects and mechanism were also investigated by using MC38 tumor-bearing mice model and immune cell depletion tumor model.

Results: PVR was over-expressed in many tumor tissues and cancer cell lines, making it a promising therapeutic target. Through virtual screening, binding, and blocking assay, liothyronine was discovered to bind PVR and block the interaction of TIGIT/PVR. Liothyronine could enhance the function of $\mathrm{CD}^{+}$and $\mathrm{CD} 8^{+} \mathrm{T}$ cells in PBMCs. Besides, in the Jurkat-hTIGIT and CHOK1-hPVR coculture assay, liothyronine could reverse the IL-2 secretion inhibition resulted by TIGIT/PVR ligation. Although had no influence on the proliferation of tumor cells in vitro, liothyronine could significantly inhibit tumor growth when administrated in vivo, by enhancing $C D 8^{+} T$ cell infiltration and immune responses in the tumor bearing mice. The immune cell depletion model showed that the anti-tumor effects of liothyronine depends on $\mathrm{CD} 4^{+} \mathrm{T}$ cells, $\mathrm{CD} 8^{+} \mathrm{T}$ cells and NK cells.
\end{abstract}

Conclusions: A small molecule liothyronine was discovered to serve as a potential candidate for cancer immunotherapy by blocking the immune checkpoint TIGIT/PVR.

Keywords: PVR, TIGIT, Small molecule compound, Virtual screening, Liothyronine, Cancer immunotherapy

\footnotetext{
* Correspondence: chenjhpush@126.com; gaoyf29@mail.sysu.edu.cn

†Junhui Chen and Yanfeng Gao these authors jointly supervised this work.

'Intervention and Cell Therapy Center, Peking University Shenzhen Hospital,

Shenzhen Peking University-The Hong Kong University of Science and

Technology Medical Center, Shenzhen 518035, China

Full list of author information is available at the end of the article
}

\section{$\triangle B M C$}

C C The Author(s). 2020 Open Access This article is licensed under a Creative Commons Attribution 4.0 International License, which permits use, sharing, adaptation, distribution and reproduction in any medium or format, as long as you give appropriate credit to the original author(s) and the source, provide a link to the Creative Commons licence, and indicate if changes were made. The images or other third party material in this article are included in the article's Creative Commons licence, unless indicated otherwise in a credit line to the material. If material is not included in the article's Creative Commons licence and your intended use is not permitted by statutory regulation or exceeds the permitted use, you will need to obtain permission directly from the copyright holder. To view a copy of this licence, visit http://creativecommons.org/licenses/by/4.0/ The Creative Commons Public Domain Dedication waiver (http://creativecommons.org/publicdomain/zero/1.0/) applies to the data made available in this article, unless otherwise stated in a credit line to the data. 


\section{Background}

Immune checkpoint blockade based cancer immunotherapy has achieved unprecedented success, represented by PD-1/PD-L1 blockade [1]. However, the response rate of $\mathrm{PD}-1 / \mathrm{PD}-\mathrm{L} 1$ blockade therapy varies greatly among patients with different types of tumors, which is urgent to be improved [2]. Another treatment dilemma is that adaptive resistance is observed in patients who initially exhibit effective response to PD-1/ PD-L1 antibody [3]. Therefore, various combination strategies were investigated to get better therapeutic efficacy, such as PD-1/PD-L1 blockade combined with radiotherapy or chemotherapy [4]. On the other hand, great progress has achieved in discovering novel immune checkpoints which could also synergize with PD-1/PDL1 and were non-redundant in restricting the antitumor response of immune cells, such as TIGIT, LAG-3, TIM-3 and CD47 [5]. Among these, TIGIT was found to be expressed not only on immune cells (such as $\mathrm{CD}^{+} \mathrm{T}$ and NK cells), but also on tumor cells, which making it a potential target for cancer immunotherapy [6].

The dominant ligand of TIGIT, poliovirus receptor PVR (also known as CD155 and Nectin like-5), was firstly identified for its ability to serve as the cellular receptor for poliovirus [7]. PVR is a cell surface glycoprotein with V-C2-C2 domain, and belongs to both immunoglobulin superfamily and Nectin/Necl family. Initial studies mainly focused on its role in mediating virus invasion and as an adhesion-related molecule for tumor invasion and migration $[8,9]$. Subsequently, PVR was identified as the ligand of co-stimulatory molecule CD226 and co-inhibitory immune checkpoint TIGIT, indicating more attention should be paid to its importance in cancer immunity $[10,11]$. It has been reported that PVR was highly expressed in a variety of tumors, including colorectal cancer, breast cancer, small cell lung cancer, head and neck squamous cell carcinoma, melanoma and gastric cancer [12-15]. PVR interacts with the immunoglobulin variable (IgV) domain of TIGIT and forms a tetramer to deliver inhibitory signals [16]. TIGI T/PVR ligation could disrupt the granule polarization and cytotoxicity of NK cells and suppress the anti-virus and anti-tumor activity of $\mathrm{CD} 8^{+} \mathrm{T}$ cells $[17,18]$. TIGIT blockade alone or with PD-1/PD-L1 or TIM-3 could significantly restore the function of $\mathrm{CD}^{+} \mathrm{T}$ cells and inhibit tumor growth in both tumor models and clinical trials [2, 18-20]. Besides, PVR blockade could reduce the experimental metastasis of osteosarcoma [21].

The development of agents for immune checkpoint blockade mainly focused on antibodies. In recent years, an increasing number of low molecular weight inhibitors such as peptides and small molecules have been investigated and showed great application prospects. They have shown strong tissue penetration, weak immunogenicity, and can be easily modified. The first proteolytic resistant D-enantiomer peptide targeting PD-L1, and a cyclic peptide of LAG-3 developed by our group exhibited significant tumor inhibition as candidates for cancer immunotherapy $[22,23]$. Besides, small molecules targeting immune checkpoints are under rapid development with great progress [24, 25]. Orally bioavailable small molecule CA170 for dual blockade of PD-L1 and VISTA is undergoing clinical trials [26]. However, small molecules for TIGIT/PVR blockade have not been investigated.

The resolution of the crystal structure of TIGIT/PVR complex makes docking based virtual screening targeting PVR feasible, which could reduce the amount of small molecule compounds tested by biochemical assays, and significantly improve the discovery efficiency. Natural products from plants, animals, marine life, bacteria, and other organisms are important resources for modern drug discovery and have played significant role in anticancer drug discovery and development [27]. The biological relevance and structural diversity make natural products good starting points for drug discovery.

In this study, we explored the expression of PVR analyzed by bioinformatics tools of TIMER, Oncomine, GEO database, and flow cytometry. By docking based virtual screening, we screened the natural product compounds targeting PVR. The compounds were further screened by biolayer interferometry-based binding assay and cell based blocking assay. The anti-tumor activity and potential mechanism of the candidate compound liothyronine were explored.

\section{Methods}

\section{Gene expression analysis}

TIMER is a comprehensive resource for systematic analysis of immune infiltrates across diverse cancer types (https://cistrome.shinyapps.io/timer/) [28]. It has seven modules for analysis of 32 cancer types from The Cancer Genome Atlas (TCGA) including gene, survival, mutation, somatic CNA, differential gene expression, correlation and estimation. Here, the expression level of PVR was analyzed between various types of tumor and normal tissues with the differential gene expression module. The gene expression level was displayed with $\log _{2}$ RSEM.

The expression level of PVR between tumor and normal tissues was also identified using the Oncomine database (https://www.oncomine.org/resource/login.html) [29]. Relevant statistical indicators were set as follows: $P<1 \times 10^{-4}$, fold change $>2$ and gene ranking in the top $10 \%$. Besides, the outlier analysis of colorectal cancer, esophagus cancers, gastric cancers, renal cancers and leukemia were performed.

Gene expression data of PVR in colorectal primary tumors, normal tissues or polyps were downloaded from 
the National Institutes of Health Gene Expression Omnibus (GEO) database (https://www.ncbi.nlm.nih. gov/geo/). Datasets GSE37182 (probe ID: ILMN 1677305 for PVR), GSE10972 (probe ID: ILMN_1677305 for PVR) and GSE41258 (probe ID: 212662_at for PVR) were analyzed.

\section{Cell culture}

Murine colorectal cancer cell lines CT26 and MC38 were cultured in Dulbecco's Modified Eagle Medium (DMEM). Human colorectal cancer cell lines HT29 and SW620, Chinese hamster ovary cell lines CHO-K1, CHO-K1 transfected with TIGIT (referred to as CHOK1-hTIGIT or CHOK1-mTIGIT), CHO-K1 transfected with PVR (referred to as CHOK1-hPVR) and Jurkat transfected with TIGIT (referred to as JurkathTIGIT) were cultured in Roswell Park Memorial Institute (RPMI) 1640 medium. Human peripheral blood mononuclear cells (PBMCs) isolated from healthy donors were cultured in Iscove's Modified Dulbecco's Medium (IMDM). All the cells were cultured at $37^{\circ} \mathrm{C}$ with $5 \% \mathrm{CO}_{2}$ under fully humidified conditions with above media (GIBCO, Grand Island, USA) supplemented with $10 \%$ fetal bovine serum FBS (BI, USA), $100 \mathrm{U} / \mathrm{mL}$ penicillin (Solarbio, China) and $100 \mu \mathrm{g} / \mathrm{mL}$ streptomycin (Solarbio, China).

\section{Flow cytometry}

Harvested cells $\left(3 \times 10^{5}\right)$ were washed with pre-cold FACS buffer (pH 7.2 PBS containing 2\% FBS), and incubated with indicated antibodies in a final volume of $50 \mu \mathrm{L}$ FACS buffer for $30 \mathrm{~min}$. Cells were then washed with FACS buffer and re-suspended with $200 \mu \mathrm{L}$ FACS buffer for flow cytometry detection. Antibodies antihuman PVR PE (clone: 2H7CD155), mouse IgG1 K isotype control (clone: P3.6.2.8.1) were used for the detection of PVR on CHOK1-hPVR and human colorectal cell lines HT29 and SW620. Anti-mouse PVR APC (clone: TX56) and rat IgG2a $\mathrm{k}$ Isotype Control (clone: eBR2a) were used for the detection of PVR on murine colorectal cell lines CT26 and MC38. Anti-human TIGI $\mathrm{T}$ PE (clone: MBSA43), mouse IgG1 $\mathrm{\kappa}$ isotype control (clone: P3.6.2.8.1), anti-mouse TIGIT PE (clone: GIGD7) and rat IgG2a $\kappa$ isotype control (clone: eBR2a) were used for the verification of the over-expression of human or mouse TIGIT on CHOK1 and Jurkat cells. All the antibodies were purchased from eBioscience. The data were acquired by a BD FACSCalibur with CELLQuest ${ }^{\mathrm{tm}}$ software and analyzed by FlowJo.

\section{Virtual screening}

The crystal structure of the human TIGIT/PVR complex has been elucidated through X-ray crystallography with the resolution of $2.9 \AA$ (PDB ID:3UDW) and deposited in the Protein Data Bank database (PDB) (https://www. rcsb.org/). The 3D structure of PVR (chain C of 3UDW) was selected for docking followed by structure optimization with the software Molecular Operating Environment (MOE) (version: 2016.08) (Chemical Computing Group ULC, Canada). By optimization, the hydrogen number was corrected, the system was charged, two residues of the C-terminal were deleted and Protonate 3D was performed for protonation. The binding area was determined by selecting the residues in the distance of $4.5 \AA$. Binding pocket was selected by the established in silico methods by the Site Finder module of MOE. An in-house natural products library with 638 compounds were used for virtual screening. Prior to docking to the prepared structure of PVR, the structures of these compounds were washed to remove extraneous salts or adjust protonation states, in order to ensure that each structure is in a form suitable for subsequent docking. Database minimization was also performed. Molecular docking was conducted with the algorithm of MOE. The top scoring ligands were judged by scores and inspected manually with specific attention to their conformations and the interactions with the pocket. Twenty-two compounds were selected for in vitro analysis and purchased from commercial suppliers (TargetMol).

\section{Biolayer interferometry-based (BLI) binding assay}

BLI experiments were performed in PBS supplemented with $0.1 \%(\mathrm{w} / \mathrm{v})$ BSA, $0.002 \%(\mathrm{v} / \mathrm{v})$ Tween 20 and $1 \%$ DMSO, with an Octet RED96 instrument (FortéBio), operating at $25^{\circ} \mathrm{C}$. The biotinylated PVR carrying a Cterminal AVITAG (CD5-H82E3, ACRO Biosystem) was loaded to saturation onto Super Streptavidin (SSA) biosensors (Pall/FortéBio), and blocked with $200 \mu \mathrm{L}$ biotin $(5 \mu \mathrm{g} / \mathrm{mL})$ for $60 \mathrm{~s}$. Before the assay, the PVR-labeled SSA sensors were pre-soaked in binding buffer for 30 min. The twenty-two small molecule compounds were preliminary screened for binding to PVR at a single concentration of $100 \mu \mathrm{M}$. The association of PVR with the eight small molecule compounds with response over than $0.03 \mathrm{~nm}$ was then measured at a series of concentrations. The dissociation was monitored by washing the ligand biosensors from the analyte solution to binding buffer for $60 \mathrm{~s}$. Double reference-subtracted sensorgrams were analyzed using Data Analysis 9.0 (Pall/Forte Bio), and binding responses at the end of the association phase were reported.

\section{Microscale thermophoresis (MST) binding assay}

MST assay was performed using the Monolith NT.115 system to determine the affinity of SMC 14 to human and mouse PVR protein. Human PVR (CD5-H5223, ACRO Biosystem) and mouse PVR (50259-M08H, Sino 
Biological) were both fused with a His tag. The protein was labeled with Red-NHS647 dye (NanoTemper Technologies $\mathrm{GmhH}$, Germany) and used for the subsequent test. SMC 14 was 2 -fold serially diluted from $100 \mu \mathrm{M}$ and 16 samples were subsequently tested. Equal volume of Red-NHS647 dye-labeled protein was incubated with the SMC 14 for $5 \mathrm{~min}$ at room temperature, the mixture was loaded onto standard capillaries for detection. The $K_{D}$ values were calculated with analysis software (MO.Affinity Analysis v2.2.4).

\section{Cell based blocking assay}

CHOK1-TIGIT cells stably expressing human or mouse TIGIT were established by lenti-viral infection followed by puromycin selection according to the previous report [6]. Cell based blocking assay was performed according to the previous report [30]. Briefly, PVR-Fc protein was incubated with a series dilution of small molecule compounds or control buffer on ice for $30 \mathrm{~min}$, human PVRFc (CD5-H82F6, ACRO Biosystem) and mouse PVR-Fc (50259-M03H, Sino Biological) were used at concentrations of 10 and $40 \mathrm{ng} /$ test, respectively. Then the mixture of PVR protein and compounds were incubated with CHOK1-TIGIT cells for another $30 \mathrm{~min}$, followed by incubation with detection antibody anti-human IgG$\mathrm{PE}$ (eBioscience) for $30 \mathrm{~min}$. Cells were then washed with FACS buffer to remove the unbound fluorescent antibodies, acquired on a FACS Caliber ${ }^{\mathrm{Tm}}$ (BD Biosciences) and analyzed by FlowJo. To test the specificity of candidate compounds, similar blocking assays were performed by using PD-1 (PD-L1-Fc, 10,084-H02H, Sino Biological) and CD47 (Sirp $\alpha-F c$, SIA-H52A8, ACRO Biosystem) over-expressed CHOK1 cells. Cells incubated with corresponding $\mathrm{Fc}$ tagged protein and anti-human IgG-PE served as positive control, while cells only incubated with anti-human Fc-PE served as negative control. The mean fluorescent intensity (MFI) was recorded for calculating the blocking efficiency as the formula:

Blocking $\%=\frac{\text { MFI of positive control }- \text { MFI of tested compounds }}{\text { MFI of positive control }} \times 100 \%$.

\section{Cell viability assay}

The cytotoxic effects of indicated compound on MC38 cells were determined by MTT assay. MC38 cells were seeded into 96-well plates at a density of 3000 cells/well and allowed to grow for adhesion. Cells were treated with medium with $1 \%$ DMSO as negative control or with a series dilution of indicated compound at a concentration range of 12.5 to $100 \mu \mathrm{M}$. Cell viability was ascertained using MTT reagent (Sigma) dissolved in $5 \mathrm{mg} / \mathrm{mL}$ PBS and incubated at $37^{\circ} \mathrm{C}$ for $4 \mathrm{~h}$ in the following 3 days. Formazan crystals formed by viable cells were dissolved in $150 \mu \mathrm{L}$ DMSO in each well. MTT reduction was quantified by measuring the absorbance at $490 \mathrm{~nm}$.

\section{PBMC activation assay}

To determine whether the small compounds could stimulate lymphocyte activation, Peripheral blood mononuclear cells (PBMCs) activation assay was performed as previously reported [31, 32]. Briefly, the PBMCs were isolated from blood samples of healthy donors by the Ficoll-Paque density gradient centrifugation, and resuspended in an IMDM medium containing 10\% FBS. PBMCs were seeded into round bottom 48-well plates at a density of $4 \times 10^{5}$ cells/well, and stimulated with stimulatory antibodies of $1 \mu \mathrm{g} / \mathrm{mL}$ human anti-CD3 (clone: OKT3, eBioscience) and $0.5 \mu \mathrm{g} / \mathrm{mL}$ human antiCD28 (clone: CD28.2, eBioscience). Indicated compound $(100 \mu \mathrm{M})$ or medium with $1 \%$ DMSO as negative control were tested for the ability to enhance the activation of lymphocytes in PBMCs. Three days later, an intracellular cytokine staining assay was performed. Cells were incubated with protein transport inhibitor (Containing Brefeldin A) (BD Biosciences) for $4 \mathrm{~h}$, and stained with antibodies of human antiCD4 PerCP-Cy5.5 (clone: OKT4, eBioscience) and human anti-CD8 APC (clone: SK1, eBioscience) on ice for $30 \mathrm{~min}$. Then, cells were fixed and permeabilized each for $30 \mathrm{~min}$ with the Foxp3/Transcription Factor Staining Buffer Set (eBioscience) according to the manufacture. Permeabilized cells were then stained with human anti-IFN- $\gamma$ PE antibody (clone: 4S.B3, eBioscience) or an isotype control.

\section{Coculture assay}

Jurkat-hTIGIT and CHOK1-hPVR cells were cocultured to determine the ability of SMC 14 for TIGIT/PVR blockade. Briefly, CHOK1-hPVR were seeded into 24well plates at a density of $1 \times 10^{5}$ cells/well and allowed for cell adhesion. Jurkat-hTIGIT were added into the plates pre-cultured with CHOK1-hPVR at a density of $2 \times 10^{5}$ cells/well with the effector: target ratio of 2:1. Jurkat-hTIGIT cells were stimulated with the antihuman CD3 $(1 \mu \mathrm{g} / \mathrm{mL})$ and anti-human CD28 $(0.5 \mu \mathrm{g} /$ $\mathrm{mL})$. SMC $14(100 \mu \mathrm{M})$ were added in the coculture system, and a functional anti-TIGIT antibody (clone: A15153A, Biolegend) served as the positive control. After $44 \mathrm{~h}$ of coculture, the protein transport inhibitor was added and incubated for another $4 \mathrm{~h}$. Then the cells were harvested, washed, and followed by fixation and permeabilization. Afterwards, the permeabilized JurkathTIGIT cells were stained with anti-human IL-2 APC (MQ1-17H12, Biolegend) or isotype control antibody for $30 \mathrm{~min}$ at $4{ }^{\circ} \mathrm{C}$. 


\section{Anti-tumor experiment and ex vivo assays}

All mice experimental procedures were approved by the Ethics Committee of Zhengzhou University. Six-weekold female C57BL/6 mice (Vital River Laboratories, China) were maintained in a specific pathogen-free facility. Food and water were supplied ad libitum. Mice were acclimatized for about 1 week before the experiment. C57BL/6 mice were subcutaneously (s.c.) injected on the right flank with $1 \times 10^{6}$ syngeneic MC38 cells in $200 \mu \mathrm{L}$ PBS. One week later, tumor-bearing mice were randomized into groups of negative control (normal saline with $3 \%$ DMSO and 0.5\% Tween-80), 0.5, 1.5, 5 and $15 \mathrm{mg} / \mathrm{kg}$ of compounds or anti-TIGIT and isotype control groups. Mice were treated with $200 \mu \mathrm{L}$ control or indicated compound through intraperitoneal (i.p.) injection every other day for 2 weeks, or with $200 \mu \mathrm{g}$ anti-TIGIT (clone:1G9, Bioxcell) or isotype control mouse IgG (I5381, Sigma) through i.p. injection every 3 days for 2 weeks. Tumor sizes were measured using a digital caliper, and tumor volumes were calculated as the formula:

$$
V=\frac{1}{2} \times \mathrm{a}(\text { length }) \times \mathrm{b}(\text { width }) \times \mathrm{c}(\text { height })
$$

For indicated immune cell depletion models, MC38 mice were injected with $250 \mu \mathrm{g}$ anti-CD4 (clone: GK1.5), $200 \mu \mathrm{g}$ anti-CD8 (clone: YTS169.4) or matched rat IgG control (I4131, Sigma), $200 \mu \mathrm{g}$ anti-NK1.1 (clone: PK136) or matched mouse IgG control (I5381, Sigma) the day before the start of tumor inoculation, as well as weekly thereafter, resulting in a total of 3 injections per mouse. The depletion efficacy was confirmed by flow cytometry analysis with the blood sample of mice treated with indicated antibodies for 6 days. Mouse anti-CD45 FITC (clone: 30-F11, eBioscience), anti CD3 PerCPeFluor710 (clone: 17A2, eBioscience), anti-CD8 $\alpha$ APC (clone: 53-6.7, eBioscience), anti-CD4 APC (clone: GK1.5, eBioscience) and anti-NK1.1 PE (clone: PK136, eBioscience) were used.

Upon completion of treatment, MC38 tumor-bearing mice were sacrificed, and the tumors were dissected and digested by $100 \mathrm{U} / \mathrm{mL}$ collagenase IV (Invitrogen) and $100 \mathrm{U} / \mathrm{mL}$ Dnase I (Sigma) for $60 \mathrm{~min}$, and then filtered through a $70 \mu \mathrm{m}$ nylon cell strainer to single cell suspension. The cells were incubated with mouse anti-CD45 FITC (clone: 30-F11, eBioscience), mouse anti-CD3 PerCP-eFluor710 (clone: 17A2, eBioscience), and mouse anti-CD8 $\alpha$ APC (clone: 53-6.7, eBioscience) to detect the frequency of infiltrating $\mathrm{CD}^{+} \mathrm{T}$ cells. For functional assay, the tumor-infiltrating lymphocytes were isolated from tumor cell suspension by discontinuous Percoll density gradients (40 and 70\%) (GE Healthcare). The isolated tumor-infiltrating lymphocytes, splenocytes and draining lymph node cells prepared by gentle mechanical disruption were stimulated with or without $20 \mathrm{ng} / \mathrm{mL}$ phorbol 12-myristate 13-acetate (PMA, Sigma) and 1 $\mu$ Mionomycin (Sigma) in the presence of protein transport inhibitor for $4 \mathrm{~h}$. The following procedure of intracellular cytokine staining assay was performed as mentioned above, and the antibodies for the staining were mouse anti-CD3 PerCP-eFluor710, mouse anti$\mathrm{CD} 8 \alpha \mathrm{PE}$, and mouse anti-IFN- $\gamma$ APC (clone: XMG1.2, eBioscience).

\section{Statistical analysis}

The data were shown as means \pm SEM, and the statistical analysis was conducted with paired or unpaired Student's $t$-test for the differences between groups. ${ }^{*} P<0.05$, ${ }^{* *} P<0.01$, and ${ }^{* * * *} P<0.001$ were considered statistically significant.

\section{Results}

The expression analysis of PVR in tumor tissues and cell lines

To confirm the expression of PVR in tumors, we firstly analyzed the data from TCGA using the tools TIMER. As shown in Fig. 1a, PVR expressed in head and neck cancer (HNSC), lung adenocarcinoma (LUAD) and stomach cancer (STAD), which was consistent with the previous study [13, 15, 33]. In addition, it also expressed across a broad spectrum of cancers including bladder cancer (BLCA), endometrioid cancer (UCEC), esophageal cancer (ESCA), kidney chromophobe (KICH), Kidney papillary cell carcinoma (KIRP), prostate cancer (PRAD), thyroid cancer (THCA), and especially in colon cancer (COAD) and rectal cancer (READ) within 50 datasets. Meanwhile, PVR expression was also analyzed in Oncomine, which PVR expressed higher in colorectal cancers, esophagus cancers, gastric cancers, renal cancers and leukemia than corresponding normal tissues. The gene rank information was shown in Fig. 1b. The further analysis focused on colorectal cancer observed that PVR expressed higher in colorectal cancer tissues than normal tissues to both non-paired samples of GSE37182 and 24 paired samples of GSE10972. More importantly, by analyzing the GSE41258 dataset, we observed that the expression level of PVR was gradually upregulated during the tumor development from normal colon to polyps and primary tumors (Fig. 1c). Besides, the flow cytometry results also showed that PVR expressed on both human and murine colorectal cancer cell lines (Fig. 1d). These results suggested that PVR might be a potential target for the treatment of colorectal cancer.

\section{Virtual screening of small molecule compounds targeting PVR}

The crystal structure of TIGIT/PVR complex had been released, which provides a structure basis for the drug 
A

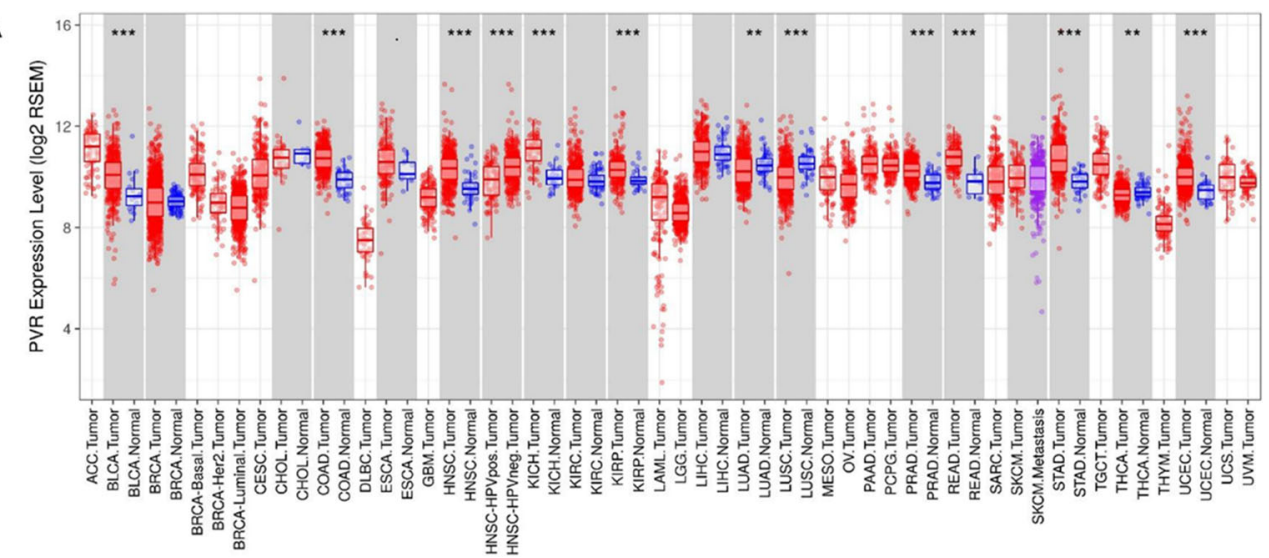

B

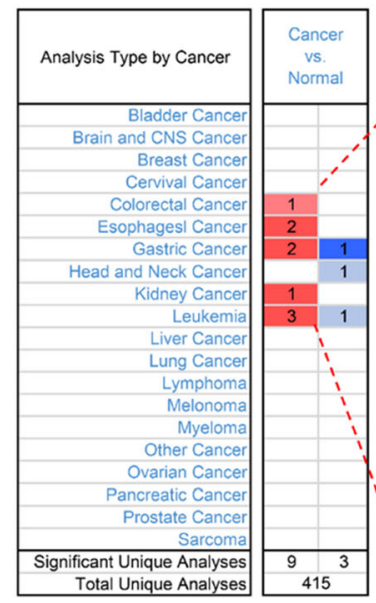

놀

\begin{tabular}{|c|c|c|c|}
\hline Datasets & $P$ value & $\begin{array}{c}\text { Fold } \\
\text { Change }\end{array}$ & $\begin{array}{l}\text { Overexpression } \\
\text { Gene Rank }\end{array}$ \\
\hline Hong colorectal (82) & $1.38 \mathrm{E}-07$ & 2.07 & 1909 (in top 10\%) \\
\hline Kimchi Esophagus (24) & 1.97E-04 & 2.222 & 152 (in top $10 \%$ ) \\
\hline Kim Esophagus (118) & $1.23 \mathrm{E}-07$ & 2.285 & 685 (in top 4\%) \\
\hline \multirow{2}{*}{ DErrico Gastric (69) } & $1.55 \mathrm{E}-10$ & 2.605 & 487 (in top 3\%) \\
\hline & $7.27 \mathrm{E}-04$ & 2.455 & 1509 (in top 8\%)) \\
\hline Yusenko Renal (67) & $9.67 \mathrm{E}-04$ & 2.201 & 606 (in top $4 \%$ ) \\
\hline \multirow{3}{*}{$\begin{array}{c}\text { Andersson } \\
\text { Leukemia } \\
\text { (127) }\end{array}$} & $3.68 \mathrm{E}-08$ & 4.282 & 250 (in top $3 \%$ ) \\
\hline & $1.07 \mathrm{E}-07$ & 5.154 & 918 (in top $9 \%$ ) \\
\hline & $2.69 \mathrm{E}-06$ & 2.451 & 941 (in top 9\%) \\
\hline
\end{tabular}

C

GSE37182

GSE10972
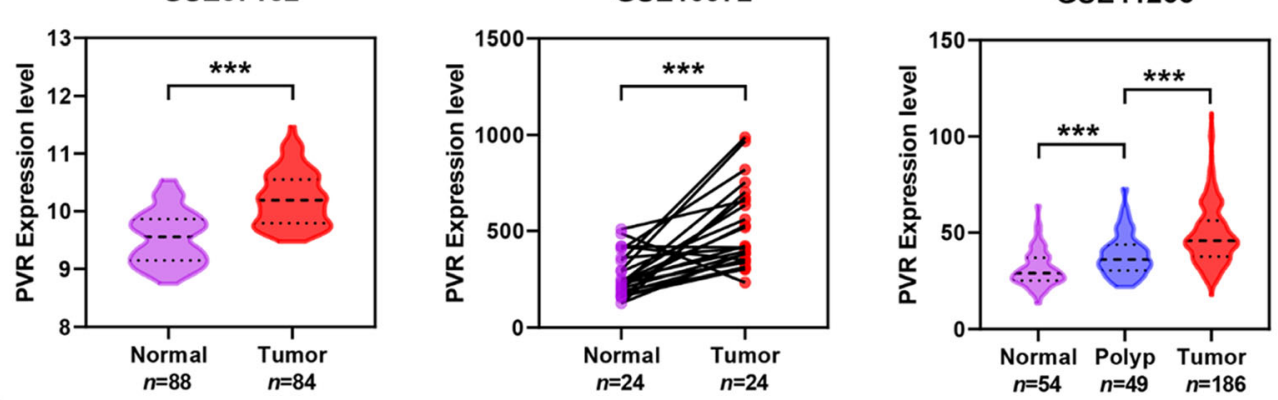

D

HT29

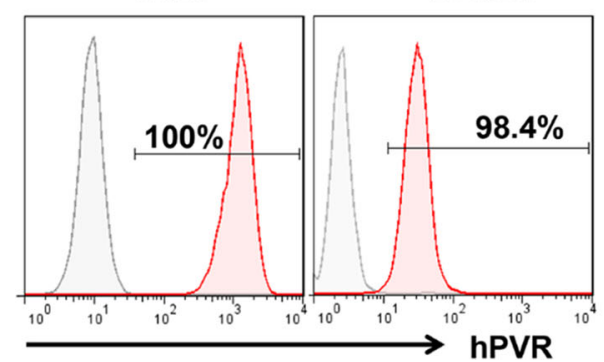

СT26

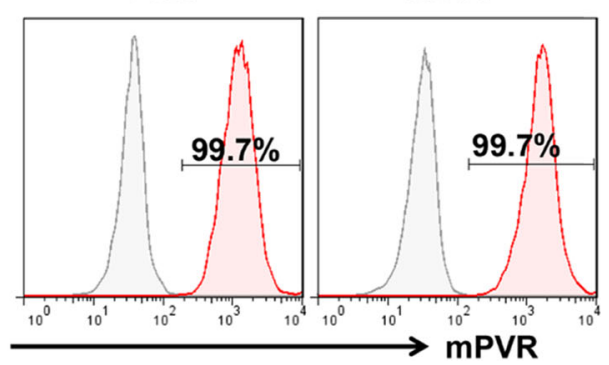

Fig. 1 (See legend on next page.) 
(See figure on previous page.)

Fig. 1 The expression level of PVR in tumor tissues and cell lines. a Human PVR expression levels in different tumor types from TCGA database were determined by TIMER $\left({ }^{*} P<0.05,{ }^{* *} P<0.01,{ }^{* * *} P<0.001\right)$. b Increased or decreased PVR expression in datasets of different cancers compared with normal tissues in the Oncomine database. (Threshold: $P<0.001$, fold change $>2$, gene ranking of top 10\%). c PVR expression level in colorectal cancers, polyps and normal tissues from GEO cohorts. Statistical analysis was conducted with unpaired Student's $t$-test for datasets GSE37182 and GSE41258, and conducted with paired Student's $t$-test for dataset GSE10972. ${ }^{* * *}, P<0.001$. d Flow cytometry analysis of PVR expression on human and murine colorectal cell lines. The red-shaded histogram represents anti-human PVR PE (left). The red-shaded histogram represents anti-mouse PVR APC (right). The gray-shaded histogram represents the matched isotype control. Representative histogram of three independent experiments were shown

discovery targeting PVR. To screen small molecule compounds blocking TIGIT/PVR interaction, the structure of PVR was prepared by correcting the hydrogen numbers, deletion of two residues in the C-terminal, and followed by protonation. The residues of PVR in a distance of $4.5 \AA$ to TIGIT (chain A of 3UDW) was labeled as the binding area (Fig. 2a). Five binding pockets were determined using the Site Finder module of MOE (supplemental Table 1). The binding pocket occupies different regions of PVR, and the second pocket is the only one close to the binding area of TIGIT/PVR and has overlaid part with the binding area, upon which we may discover small molecule compounds occupy the area in purple and interfere the interaction of TIGIT and PVR. The residues form this binding pocket were selected for subsequent molecular docking (Fig. 2b). The compounds of natural product library were washed, performed energy minimization, and docked to the structure prepared PVR. The compounds were screened as the procedure shown in Fig. 2c. With comprehensive consideration of the molecular weight, S-score which represents the binding energy, and especially the

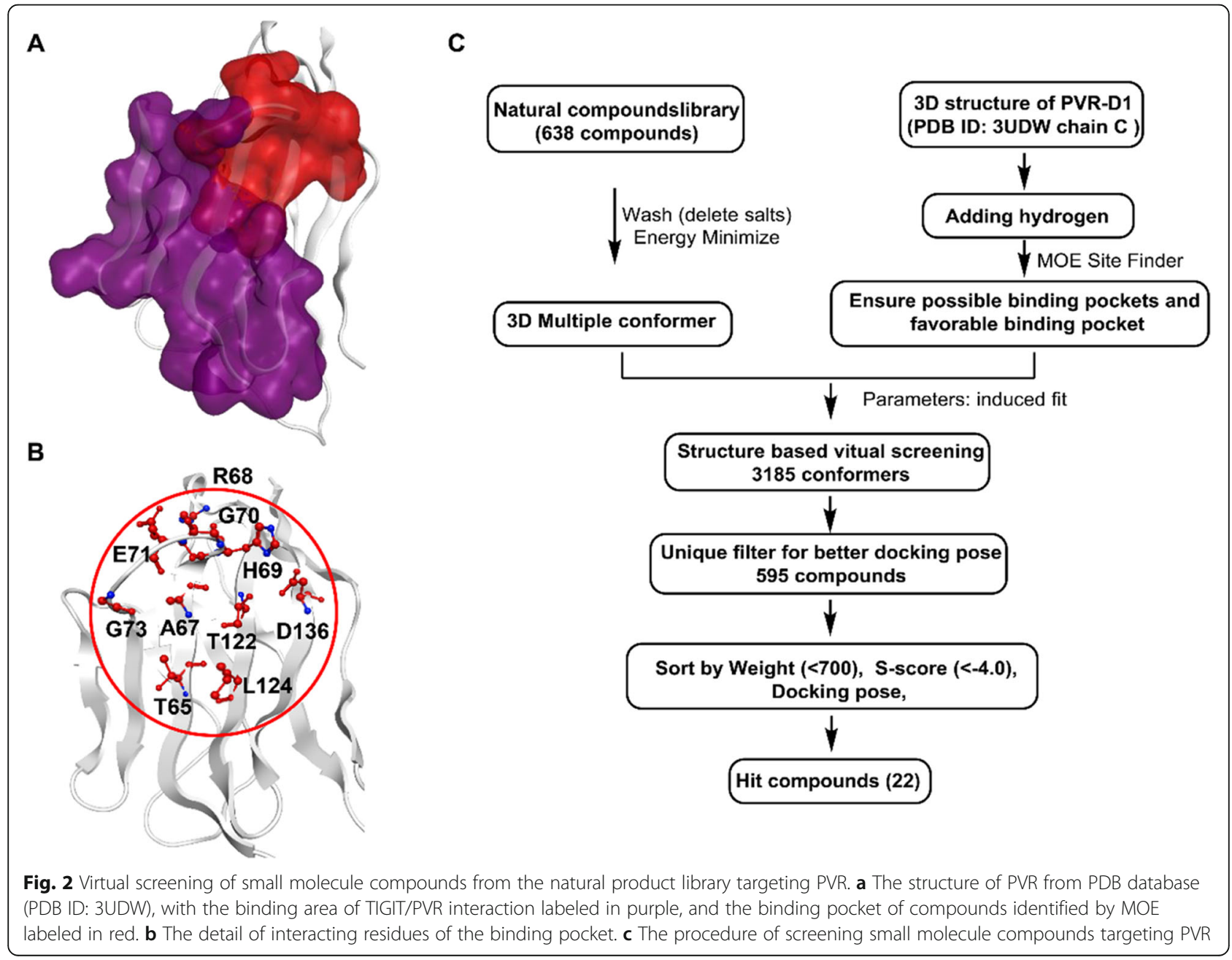


conformations and interactions with the pocket, twentytwo candidate compounds were selected for further biochemical assays. The detail information of candidate compounds was shown in supplemental Table 1.

\section{The biochemical evaluation of candidate compounds by}

BLI

The binding affinity of all the candidate compounds targeting PVR were tested by the double referencesubtracted BLI assay as depicted in Fig. 3a. The test was initialed with a primary screening with a single concentration of $100 \mu \mathrm{M}$, and eight compounds exhibited relative high response above $0.03 \mathrm{~nm}$ (Fig. $3 \mathrm{~b}$ ). The eight compounds were further tested with a series of concentrations for obtaining the $K_{D}$ values to PVR protein, and three compounds, SMC 6, SMC 14 and SMC 22 possessed high affinities to PVR with $K_{D}$ values of $42 \mu \mathrm{M}$, $12 \mu \mathrm{M}$, and $5.9 \mu \mathrm{M}$, respectively (Fig. 3c). The other five compounds, including SMC 2 with the relatively good response, could not fit a determined $K_{D}$ value with the binding and dissociation curves at series concentrations.

\section{Screening of the candidate compounds by cell based blocking assay}

The ability of these three compounds for blocking TIGI T/PVR were further tested by cell based blocking assay with CHOK1-hTIGIT cells as depicted in Fig. 4a. Human PVR protein with an Fc tag was used to bind to the cell membrane TIGIT and served as the positive control. In the blocking assay, SMC 22 exhibited extremely low blocking efficacy, and SMC 6 had a moderate blocking efficacy of $52 \%$ at the highest concentration. SMC14 (liothyronine) could significantly block the ligation of PVR and TIGIT in a dose dependent manner with the $\mathrm{IC}_{50}$ of $6.1 \mu \mathrm{M}$ (Fig. 4b). The blockade of human TIGIT/ PVR by liothyronine at different concentrations was shown in Fig. 4c. Further, the blocking efficacy of mouse TIGIT/PVR was tested by using mPVR protein and CHOK1 cells overexpressing mTIGIT, and liothyronine could also block the interaction of mouse PVR and TIGI $\mathrm{T}$ (Fig. 4d). Considering that the blocking efficacy of mouse TIGIT/PVR is lower than that of human TIGIT/ PVR, the affinity of SMC 14 to human and mouse PVR was also tested by MST assay. SMC 14 could bind to mPVR with the $K_{D}$ value of $2.64 \mu \mathrm{M}$ and bind to hPVR with a lower $K_{D}$ value of $0.36 \mu \mathrm{M}$ (Fig. S1), and the difference of the affinity may explain the blocking efficacy of human and mouse TIGIT/PVR interaction. As the binding model shown in Fig. S2, liothyronine could be docked to PVR in the binding pocket and interact with the residues at the binding area of TIGIT. Considering that most of the immune checkpoint molecules interact with their ligands or receptors through the IgV-like domain, and shared certain structural similarities, the activities of liothyronine in PD-1/PD-L1 and CD47/Sirp $\alpha$ cell based blocking system were also tested. Liothyronine could not block the interaction of PD-1/PD-L1 nor CD47/Sirpo, indicating its specificity targeting TIGIT/ PVR (Fig. S3a, b).

\section{The effects of liothyronine on colorectal tumor cells and immune cells in vitro}

Then, the in vitro cytotoxic activity in colorectal tumor cells and immune modulating effects on PBMCs of liothyronine were determined. The results suggested that liothyronine did not impact the cell viability of MC38 cells at the tested concentrations (Fig. 5a). To determine the functional result of TIGIT/PVR blockade by SMC 14, a PBMCs activation assay was performed. Similar as described previously, [11] TIGIT was expressed on the PBMCs stimulated by anti-CD3 and anti-CD28 antibodies (Fig. 5b). Since PVR was also expressed on PBMCs, the TIGIT/PVR ligation would suppress the $\mathrm{T}$ cell activation. The addition of liothyronine in the stimulated PBMCs could significantly restore the secretion of IFN- $\gamma$ by $\mathrm{CD}_{4}^{+}$and $\mathrm{CD} 8^{+} \mathrm{T}$ cells (Fig. $5 \mathrm{~b}$ ). Besides, a coculture assay was also performed using the CHOK1hPVR cells and TIGIT overexpressing Jurkat cells which was widely used as $\mathrm{T}$ cells for immune checkpoint blockade assays (Fig. 5c). TIGIT/PVR interaction could significantly inhibit the IL-2 secretion of Jurkat-hTIGIT cells, while a functional anti-TIGIT antibody and SMC 14 could significantly reverse the inhibition (Fig. 5d). Therefore, our results revealed that liothyronine did not affect the proliferation of tumor cells, but significantly enhanced the function of $\mathrm{T}$ cells, indicating liothyronine has the typical characteristics of immune checkpoint blockers.

\section{Liothyronine could inhibit tumor growth and elicit immune response in mice}

To explore the anti-tumor effects of liothyronine in mice, we firstly tested the potential side effects at different concentrations administrated for at least one week. There were no obvious effects on mental state, weight and diet of the mice. Then, the anti-tumor effects of liothyronine were tested on the MC38 tumor model. We firstly selected four concentrations of liothyronine $(0.5$, $1.5,5,15 \mathrm{mg} / \mathrm{kg}$ ), and $0.5 \mathrm{mg} / \mathrm{kg}$ liothyronine showed almost no anti-tumor effects, and the anti-tumor effects of 5 and $15 \mathrm{mg} / \mathrm{kg}$ liothyronine is equivalent. Then the two concentrations of 1.5 and $5 \mathrm{mg} / \mathrm{kg}$ were selected for further research (Fig. S4a). Meanwhile, anti-TIGIT antibody was also used for the tumor model, and liothyronine exhibited similar tumor inhibition with the antibodies (Fig. S4b). Subsequently, to explore the mechanism of tumor inhibition by liothyronine, MC38 tumor bearing mice were injected with normal saline, low dose $(1.5 \mathrm{mg} / \mathrm{kg})$ 


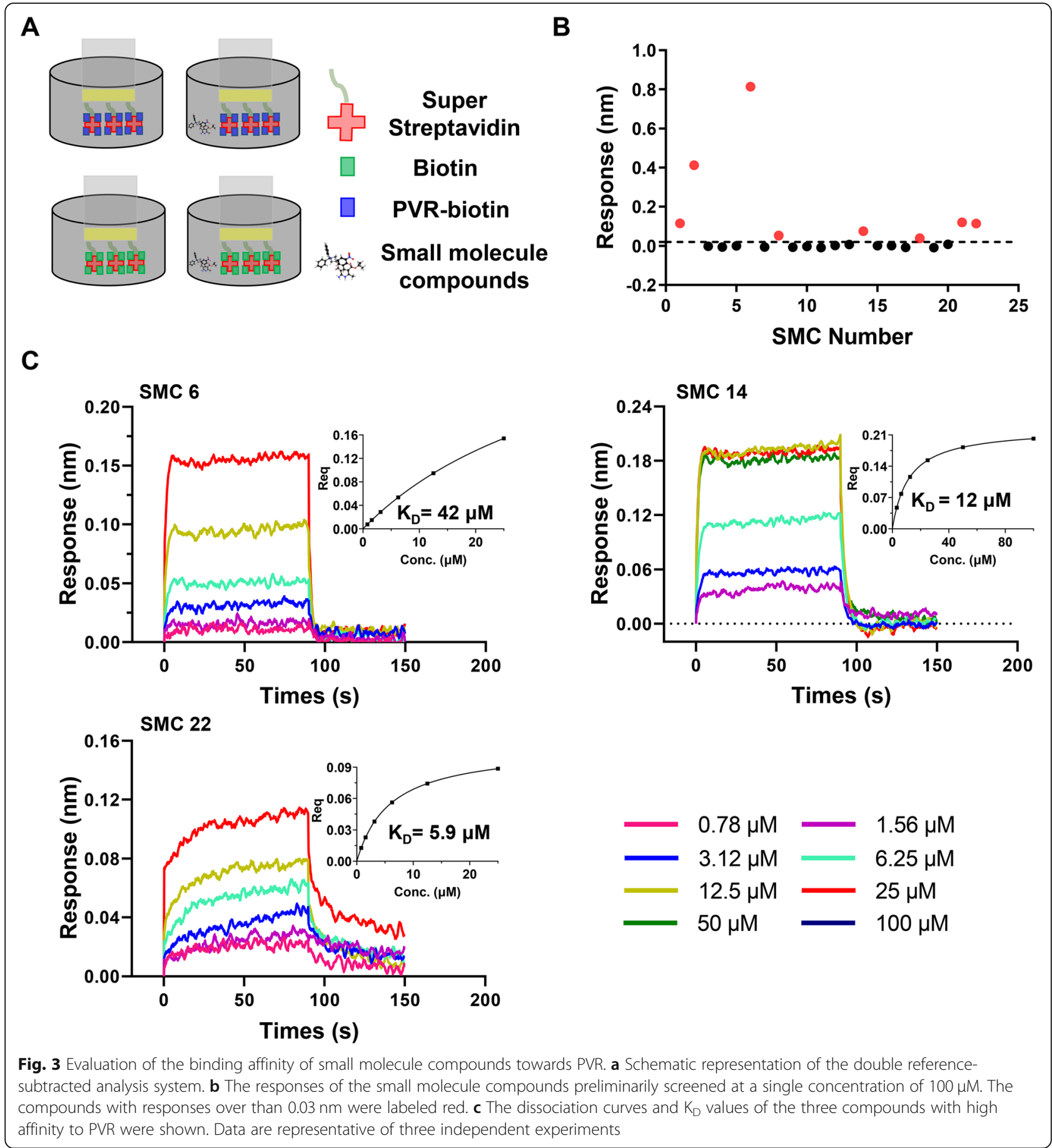

or high dose $(5 \mathrm{mg} / \mathrm{kg})$ of liothyronine. Both low dose and high dose of liothyronine could significantly inhibit MC38 tumor growth as above (Fig. 6a). Further, liothyronine could significantly augment the frequency of tumor infiltrating $\mathrm{CD}^{+} \mathrm{T}$ cells, and significantly enhanced the secretion of IFN- $\gamma$ by tumor infiltrating $\mathrm{CD}^{+} \mathrm{T}$ cells treated with high dose of liothyronine (Fig. $6 \mathrm{~b}, \mathrm{c})$. The systemic immune response was also explored, and low dose of liothyronine could significantly elicit immune responses by increasing the frequency of $\mathrm{CD}^{+}$ IFN $-\gamma^{+} \mathrm{T}$ cells in the tumor draining lymph node but not in the spleen, while high dose of liothyronine could increase the frequency in both tissues (Fig. 6d, e). Thus, liothyronine could suppress tumor growth and stimulate $\mathrm{CD}^{+} \mathrm{T}$ cell response in tumor bearing mice. Since that the TIGIT/PVR immune checkpoint axis plays a major 


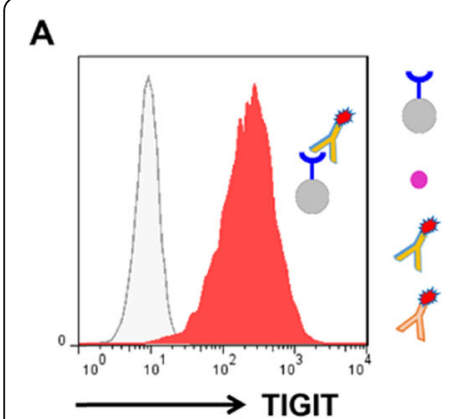

B

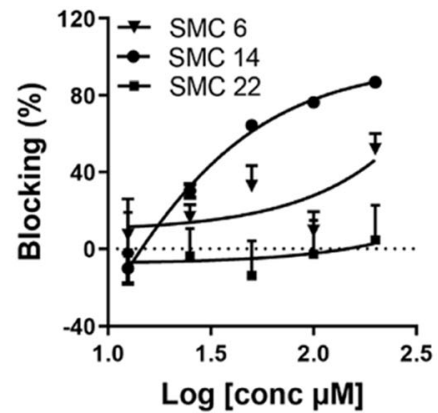

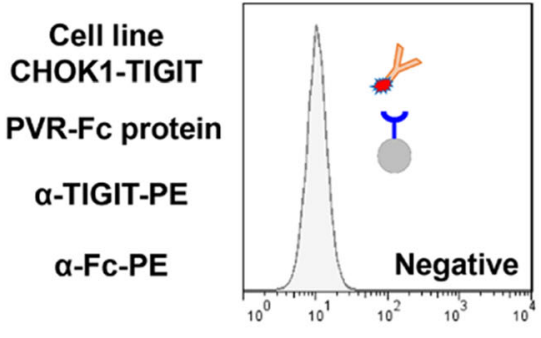

C

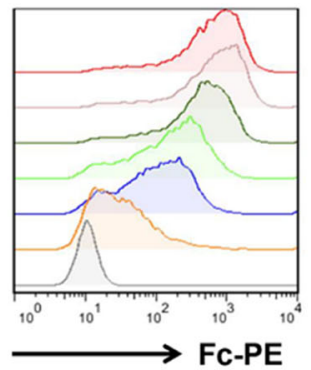

hPVR-FC

12.5

25

50

100

$200 \mu \mathrm{M}$

CHOK1-hTIGIT
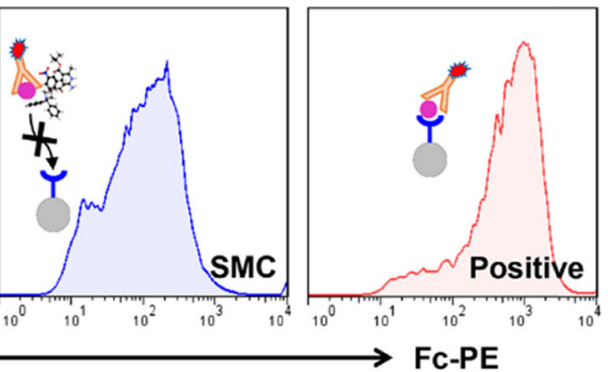

D

Fig. 4 The blocking efficacy of TIGIT/PVR interaction by small molecule compounds. a Schematic representation of cell based blocking assay. The TIGIT expression level on CHOK1-hTIGIT cells were confirmed (Left). The representative FACS histogram of tested compounds, cells only incubated with anti-human IgG-PE served as the negative and cells incubated with human PVR-Fc protein served as the positive control (Right). b The dose dependent blocking curves of SMC 6, SMC 14 and SMC 22 were shown. (c and d) The representative FACS histogram of blocking assay of SMC 14 with CHOK1-hTIGIT $\mathbf{c}$ and CHOK1-mTIGIT cells $\mathbf{d}$ were shown. Data are representative of at least three independent experiments

role in the functional regulation of $\mathrm{T}$ cells and NK cells, we also explored the role of $\mathrm{CD} 4^{+}, \mathrm{CD} 8^{+} \mathrm{T}$ and NK cells in the tumor inhibition mediated by liothyronine therapy. T cells and NK cells depletion tumor models were established, and the depletion efficacy was verified by flow cytometry (Fig. S5). With injection of rat IgG or mouse IgG controls, liothyronine could also inhibit the MC38 tumor growth same as in Fig. 6a (Fig. 6f, g), while with the $\mathrm{CD} 4^{+}, \mathrm{CD} 8^{+} \mathrm{T}$ and NK cells depleted by indicated depletion antibodies, the anti-tumor effects of liothyronine almost disappeared. The results demonstrated that the therapeutic effects of liothyronine depends on the existence of $\mathrm{CD} 4^{+}, \mathrm{CD} 8^{+} \mathrm{T}$ and NK cells.

\section{Discussion}

Although cancer immunotherapy based on PD-1/PD-L1 blockade has gained sustain progress, the low response rate and adaptive resistance make a deep investigation of other immune checkpoints urgently needed. The novel immune checkpoint TIGIT expressed on NK cells, activated $\mathrm{CD} 8^{+} \mathrm{T}$ cells, effector $\mathrm{CD} 8^{+} \mathrm{T}$ cells and regulatory $\mathrm{T}$ cells (Tregs), and suppressed the anti-tumor immune response by interacting with PVR [19, 20, 34]. Our previous study revealed the expression of TIGIT on colorectal tumor cells and its pivotal role in colorectal cancers [6].
Here, we found that PVR also overexpressed in many tumors inkling colorectal cancers, and the expression level increased during the tumor development. An increasing number of studies revealed that PVR was more than just a virus receptor, and it also played a critical role in a multitude of biological processes [35]. It is of great clinical significance to investigate the mechanism of TIGIT/PVR and develop inhibitors to block TIGIT/PVR.

Small molecules have entered the arena of cancer immunotherapy either by reducing immune suppression in the tumor microenvironment or enhancing activation of cytotoxic $\mathrm{T}$ lymphocyte responses. They have advantages over antibodies including greater penetration, oral bioavailability and fine control of bioavailability avoiding severe immune associated adverse events associated with antibodies [26]. Besides, small molecules could be easily modified or designed to combine with other cancer therapies to increase their efficacy. Small molecules dual targeting PD-L1 and VISTA (CA-170) or TIM-3 (CA-372) has been developed for cancer immunotherapy. Epacadostat, a small molecule inhibitor targeting IDO (indoleamine 2, 3-dioxygenase) has also been developed and engineered into nanoparticles for combination with 


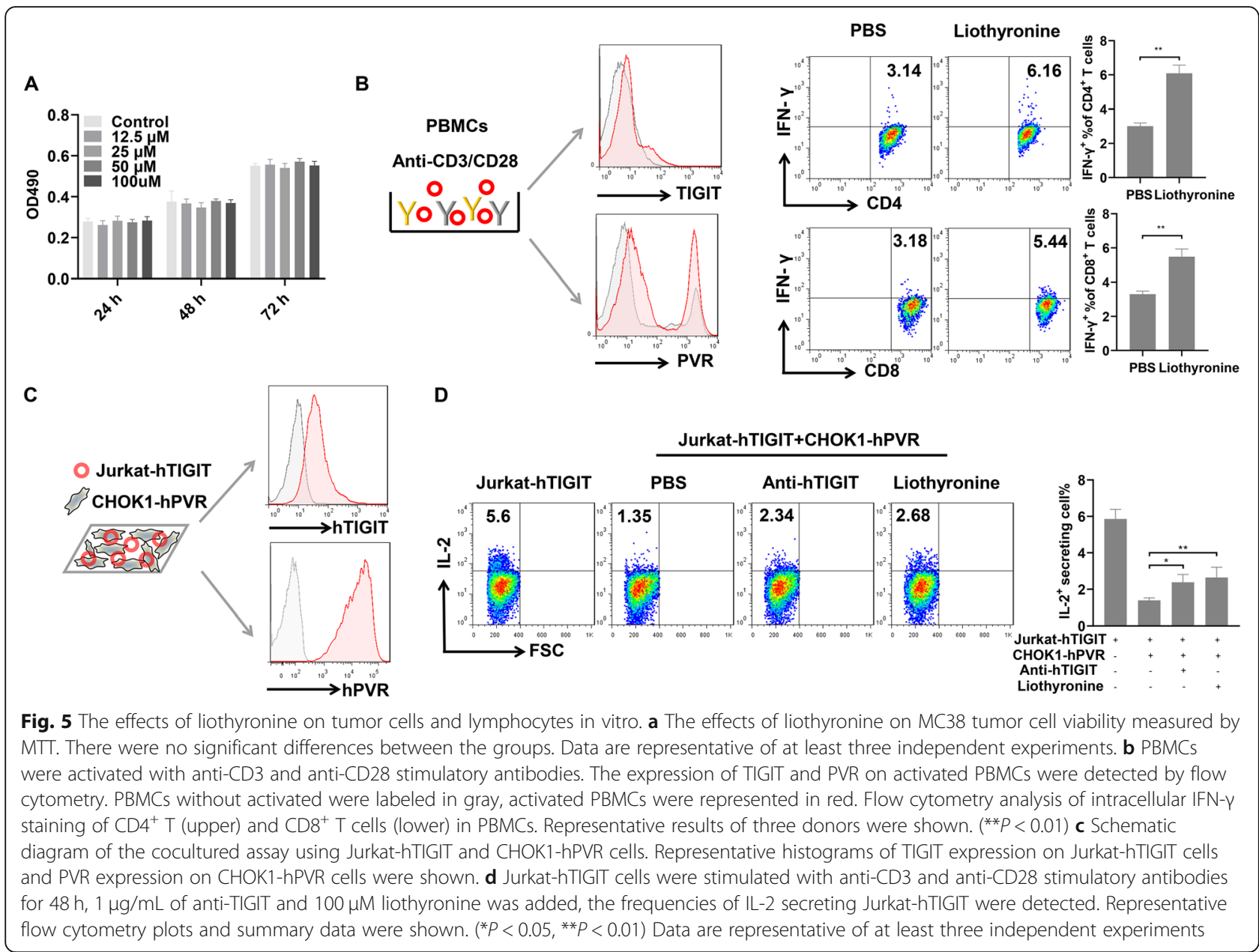

photothermal therapy [36]. However, the small molecules targeting TIGIT/PVR lags far behind.

As reported, TIGIT/PVR interacts through the "key" residue of Y113 in TIGIT and F128 in PVR with the corresponding "lock" formed by $\mathrm{AX}_{6} \mathrm{G}$ motif, and possesses the traditional lock-and-key interface. The interface occupies most of the typical Ig $\beta$-sandwich fold formed by the $\mathrm{A}^{\prime} \mathrm{GFCC} \mathrm{C}^{\prime} \mathrm{C}^{\prime \prime} \beta$-sheets [16]. Although it is quite difficult to design inhibitors that block the interaction between proteins, especially for smooth protein structures consisting of multiple $\beta$-sheets, we found a pocket suitable for small molecule occupancy on PVR. More importantly, the residues forming the pocket partially overlap with the key residues in the TIGIT/PVR binding area. Through a series of in vitro assays, liothyronine which could bind to PVR and efficiently block TIGIT/ PVR interaction was obtained. We further analyzed the binding model of liothyronine and PVR, liothyronine interacts with the residues which forms the pocket with a stable structure, and occupies the TIGIT/PVR binding area. The binding model may pave the road for screening other compounds and for the optimization based on liothyronine.

SMC 14, liothyronine is a synthetic form of triiodothyronine (T3) used in the treatment of hypothyroidism, nontoxic goiter, cretinism, and myxedema. Thyroid hormones play critical role in regulating the essential biological processes including proliferation, differentiation, apoptosis, and metabolism. Although large quantities of researches have supported a relationship between thyroid hormones and the pathophysiology of various cancer types, the current studies about the relationship of T3 and colorectal cancers are complicated and uncertain [37]. Recently, a research group investigated the immune-related adverse events in non-small cell lung cancer patients treated with nivolumab (antiPD-1 antibody), and reported that patients with low free tetraiodothyronine (fT4) in serum had significantly longer PFS and median overall survival than those without low fT4 [38]. As is well known that T4 could be catalyzed and transformed to T3, maybe liothyronine could block the TIGIT/PVR interaction and help to enhance 


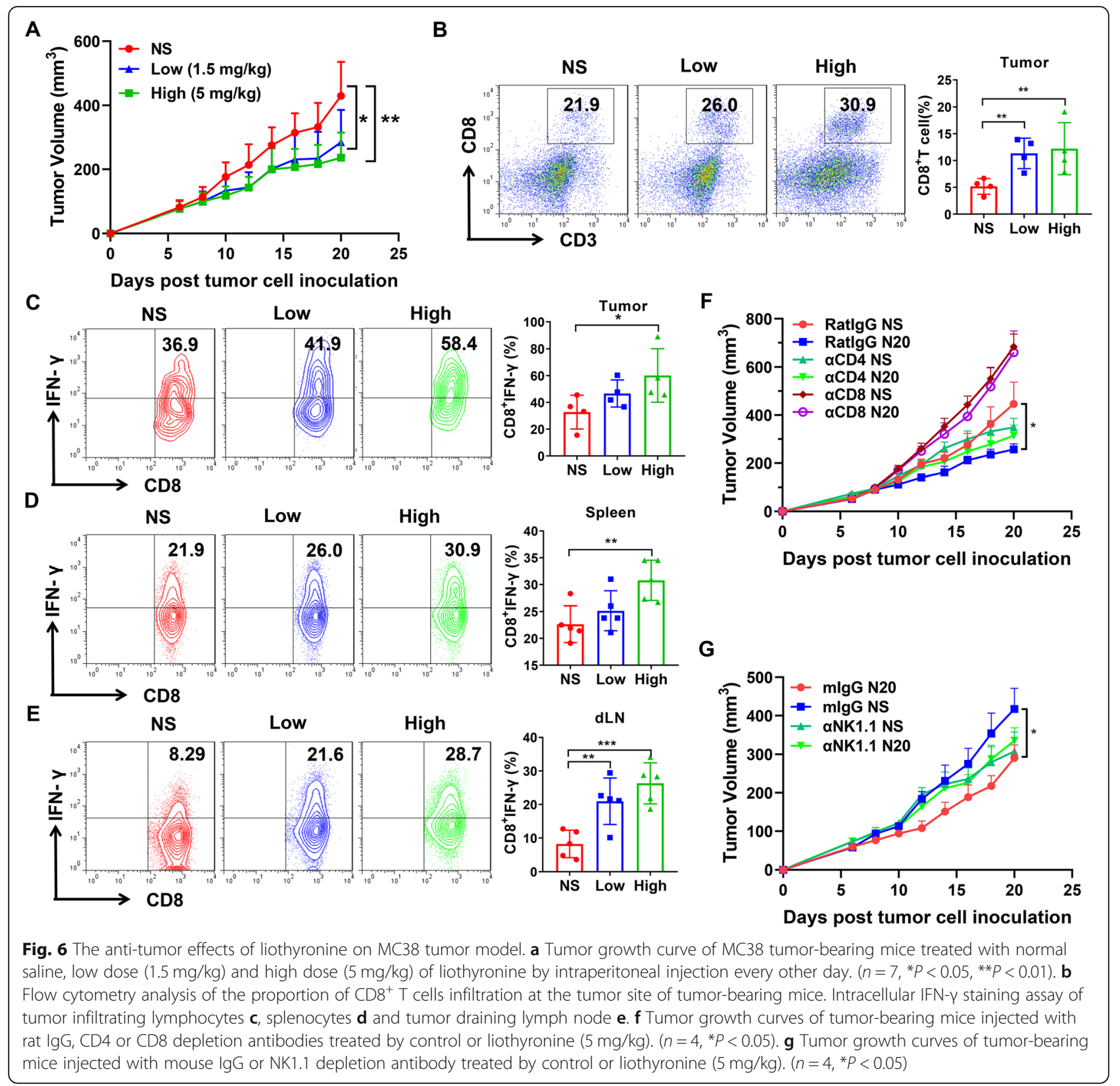

the efficacy of ani-PD-1. It has been reported that aspirin could inhibit tumor cell growth by reducing the expression level of TIGIT, and that emodin could elicit the anti-tumor effects through downregulating the expression of PVR $[39,40]$. Quite different from that, liothyronine could exert anti-tumor effects by TIGIT/PVR blockade. Liothyronine could block both human and mouse TIGIT/PVR interaction, although the blocking efficacy of mouse TIGIT/PVR is not so obvious. The differences of the efficacy may be attributed to that liothyronine has better binding affinity to human PVR than mouse PVR. Thus, through the significantly tumor inhibition on tumor model, we could infer that liothyronine may have better results in human. Different from the traditional chemotherapy drugs, liothyronine has no influence on the proliferation of tumor cells. TIGIT/PVR blockade by liothyronine could reverse the inhibition of IL-2 secretion of Jurkat cells and enhance the function of $\mathrm{T}$ cells in the activated PBMCs. The anti-tumor effects of liothyronine in the MC38 tumor model also relies on its function on immune cells. Liothyronine could increase the quantities and functional quality of tumor infiltrating $\mathrm{CD}^{+} \mathrm{T}$ cells, and exert systemic immune response. Besides, the immune cell depletion models confirmed that the anti-tumor effects of liothyronine depends on the existence of $\mathrm{T}$ cells 
and NK cells. These results suggested that liothyronine had the similar characteristics as other immune checkpoint blockers.

\section{Conclusions}

Here, we confirmed the overexpression of PVR on a broad spectrum of cancers, especially in colorectal cancers. We also developed the first small molecule, liothyronine, targeting PVR by docking-based virtual screening. Liothyronine could bind to PVR and block the interaction of TIGIT/PVR, as well as enhance the function of $\mathrm{T}$ cells in vitro. It also exerted anti-tumor effects by augmenting the tumor infiltrating quantity and function of $\mathrm{CD}^{+} \mathrm{T}$ cells. Our research provides a promising candidate for cancer immunotherapy based on TIGIT/PVR blockade.

\section{Supplementary information}

Supplementary information accompanies this paper at https://doi.org/10. 1186/s12964-020-00638-2.

Additional file 1: Figure S1. The binding affinity of SMC 14 to human and mouse PVR by MST assay. Figure S2. The binding model of liothyronine with PVR. Figure S3. The blocking efficacy of PD-1/PD-L1 and CD47/Sirpa interaction by liothyronine. Figure S4. The anti-tumor effects of liothyronine and anti-TIGIT antibody on MC38 tumor model. Figure S5. The depletion efficacy of $\mathrm{CD}^{+} \mathrm{T}, \mathrm{CD} 8^{+} \mathrm{T}$ and NK cells in MC38 tumor model. Table S1. The binding pocket for small molecules on PVR. Table S2. Candidate compounds through virtual screening.

\section{Abbreviations}

TIGIT: T cell immunoglobulin and immunoreceptor tyrosine-based inhibitory motif domain; PVR: Poliovirus receptor; GEO: Gene Expression Omnibus; TCGA: The Cancer Genome Atlas; MOE: Molecular operating environment; BLI: Biolayer interferometry; PBMCs: Peripheral blood mononuclear cells; MTT: 3-(4, 5-dimethyl-2-thiazolyl)-2,5-diphenyl-2-H-tetrazolium bromide; T3: Triiodothyronine; T4: Tetraiodothyronine

\section{Acknowledgments}

Not applicable.

\section{Authors' contributions}

$Y G$ and $X Z$ conceived the research and designed the experiments; XZ, HW and CC conducted the experiments, acquired and analyzed the data with the critical assistance from JL, XC, WXZ, SC, SG and WJZ; JD and WZ guided the bioinformatic part; all authors contribute to writing the manuscript; WSZ, JC and Prof. YG revised the manuscript. All authors read and approved the final manuscript.

\section{Funding}

This work was supported by grants from National Natural Science Foundation of China (Nos. 81822043 and U1604286 for Y.G.; and Nos. 31700677 for W.Z.), the Key Incubation Fund of SYSU (19ykzd29), Sanming Project of Medicine in Shenzhen (SZSM201612071), the Key Scientific Research Projects of Henan Higher Education Institutions (18A180004) and the China Postdoctoral Science Foundation (2020 M672755).

\section{Availability of data and materials}

The datasets generated during and/or analyzed during the current study are available from the corresponding author on reasonable request.

\section{Ethics approval and consent to participate}

All mice experimental procedures were approved by the Ethics Committee of Zhengzhou University.
Consent for publication

All authors have agreed to publish this manuscript.

\section{Competing interests}

The authors declare that they have no competing interests.

\section{Author details}

${ }^{1}$ Intervention and Cell Therapy Center, Peking University Shenzhen Hospital, Shenzhen Peking University-The Hong Kong University of Science and Technology Medical Center, Shenzhen 518035, China. ${ }^{2}$ School of Life Sciences, Zhengzhou University, Zhengzhou 450001, China. ${ }^{3}$ School of Pharmaceutical Sciences (Shenzhen), Sun Yat-sen University, Shenzhen 518107, China.

Received: 26 March 2020 Accepted: 7 August 2020

Published online: 07 September 2020

\section{References}

1. Sanmamed MF, Chen L. A paradigm shift in cancer immunotherapy: from enhancement to normalization. Cell. 2018;175:313-26. https://doi.org/10. 1016/j.cell.2018.09.035.

2. Andrews LP, Yano $H$, Vignali DAA. Inhibitory receptors and ligands beyond PD-1, PD-L1 and CTLA-4: breakthroughs or backups. Nat Immunol. 2019 https://doi.org/10.1038/s41590-019-0512-0.

3. O'Donnell JS, Long GV, Scolyer RA, Teng MW, Smyth MJ. Resistance to PD1/ PDL1 checkpoint inhibition. Cancer Treat Rev. 2017:52:71-81. https://doi.org/ 10.1016/j.ctrv.2016.11.007.

4. Smyth MJ, Ngiow SF, Ribas A, Teng MW. Combination cancer immunotherapies tailored to the tumour microenvironment. Nat Rev Clin Oncol. 2016;13:143-58. https://doi.org/10.1038/nrclinonc.2015.209.

5. Kon E, Benhar I. Immune checkpoint inhibitor combinations: current efforts and important aspects for success. Drug Resist Updat. 2019;45:13-29. https://doi.org/10.1016/j.drup.2019.07.004.

6. Zhou X-M, Li W-Q, Wu Y-H, Han L, Cao X-G, Yang X-M, et al. Intrinsic expression of immune checkpoint molecule TIGIT could help tumor growth in vivo by suppressing the function of NK and CD8+ T cells. Front Immunol. 2018;9:2821. https://doi.org/10.3389/fimmu.2018.02821.

7. Mendelsohn CL, Wimmer E, Racaniello VR. Cellular receptor for poliovirus: molecular cloning, nucleotide sequence, and expression of a new member of the immunoglobulin superfamily. Cell 1989; 56, 855-865. doi: doi.org/ https://doi.org/10.1016/0092-8674(89)90690-9.

8. Sloan KE, Eustace BK, Stewart JK, Zehetmeier C, Torella C, Simeone M, et al. CD155/PVR plays a key role in cell motility during tumor cell invasion and migration. BMC Cancer. 2004;4:73. https://doi.org/10.1186/1471-2407-4-73.

9. Selinka HC, Zibert A, Wimmer E. Poliovirus can enter and infect mammalian cells by way of an intercellular adhesion molecule 1 pathway. Proc Natl Acad Sci U S A. 1991;88:3598-602. https://doi.org/10.1073/pnas.88.9.3598.

10. Bottino C, Castriconi R, Pende D, Rivera P, Nanni M, Carnemolla B, et al. Identification of PVR (CD155) and nectin-2 (CD112) as cell surface ligands for the human DNAM-1 (CD226) activating molecule. J Exp Med. 2003;198: 557-67. https://doi.org/10.1084/jem.20030788.

11. Yu X, Harden K, Gonzalez LC, Francesco M, Chiang E, Irving B, et al. The surface protein TIGIT suppresses T cell activation by promoting the generation of mature immunoregulatory dendritic cells. Nat Immunol. 2009. 10:48-57. https://doi.org/10.1038/ni.1674.

12. Zheng Q, Wang B, Gao J, Xin N, Wang W, Song X, et al. CD155 knockdown promotes apoptosis via AKT/BCl-2/Bax in colon cancer cells. J Cell Mol Med. 2018:22:131-40. https://doi.org/10.1111/jcmm.13301.

13. Wu L, Mao L, Liu JF, Chen L, Yu GT, Yang LL, et al. Blockade of TIGIT/CD155 signaling reverses T-cell exhaustion and enhances antitumor capability in head and neck squamous cell carcinoma. Cancer Immunol Res. 2019;7: 1700-13. https://doi.org/10.1158/2326-6066.CIR-18-0725.

14. Inozume T, Yaguchi T, Furuta J, Harada K, Kawakami Y, Shimada S. Melanoma cells control antimelanoma CTL responses via interaction between TIGIT and CD155 in the effector phase. J Invest Dermatol. 2016; 136:255-63. https://doi.org/10.1038/jid.2015.404.

15. He WL, Zhang H, Han F, Chen XL, Lin R, Wang W, et al. CD155/TIGIT signaling regulates CD8+ T cell metabolism and promotes tumor progression in human gastric cancer. Cancer Res. 2017:77:6375-88. https://doi.org/10.1158/0008-5472.can-17-0381. 
16. Stengel KF, Harden-Bowles K, Yu X, Rouge L, Yin JP, Comps-Agrar L, et al. Structure of TIGIT immunoreceptor bound to poliovirus receptor reveals a cell-cell adhesion and signaling mechanism that requires cis-trans receptor clustering. Proc Natl Acad Sci U S A. 2012;109:5399-404. https://doi.org/10. 1073/pnas.1120606109.

17. Liu S, Zhang H, Li M, Hu D, Li C, Ge B, et al. Recruitment of Grb2 and SHIP1 by the ITT-like motif of TIGIT suppresses granule polarization and cytotoxicity of NK cells. Cell Death Differ. 2013;20:456-64. https://doi.org/10. 1038/cdd.2012.141.

18. Johnston RJ, Comps-Agrar L, Hackney J, Yu X, Huseni M, Yang Y, et al. The immunoreceptor TIGIT regulates antitumor and antiviral CD8(+) T cell effector function. Cancer Cell. 2014;26:923-37. https://doi.org/10.1016/j.ccell. 2014.10.018

19. Zhang Q, Bi J, Zheng X, Chen Y, Wang H, Wu W, et al. Blockade of the checkpoint receptor TIGIT prevents NK cell exhaustion and elicits potent anti-tumor immunity. Nat Immunol. 2018;19:723-32. https://doi.org/10.1038/ s41590-018-0132-0.

20. Kurtulus S, Sakuishi K, Ngiow SF, Joller N, Tan DJ, Teng MW, et al. TIGIT predominantly regulates the immune response via regulatory $T$ cells. J Clin Invest. 2015;125:4053-62. https://doi.org/10.1172/jci81187.

21. Zhuo B, Li Y, Gu F, Li Z, Sun Q, Shi Y, et al. Overexpression of CD155 relates to metastasis and invasion in osteosarcoma. Oncol Lett. 2018;15:7312-8. https://doi.org/10.3892/ol.2018.8228.

22. Chang HN, Liu BY, Qi YK, Zhou Y, Chen YP, Pan KM, et al. Blocking of the PD-1/PD-L1 interaction by a D-peptide antagonist for cancer immunotherapy. Angew Chem Int Ed Eng. 2015;54:11760-4. https://doi.org/ 10.1002/anie.201506225.

23. Zhai W, Zhou X, Wang H, Li W, Chen G, Sui X, et al. A novel cyclic peptide targeting LAG-3 for cancer immunotherapy by activating antigen-specific CD8(+) T cell responses. Acta Pharm Sin B. 2020;10:1047-60. https://doi.org/ 10.1016/j.apsb.2020.01.005.

24. Sasikumar PG, Ramachandra M. Small-molecule immune checkpoint inhibitors targeting PD-1/PD-L1 and other emerging checkpoint pathways. BioDrugs. 2018:32:481-97. https://doi.org/10.1007/s40259-018-0303-4.

25. Adams JL, Smothers J, Srinivasan R, Hoos A. Big opportunities for small molecules in immuno-oncology. Nat Rev Drug Discov. 2015;14:603-22. https://doi.org/10.1038/nrd4596.

26. Kerr WG, Chisholm JD. The next generation of immunotherapy for cancer: small molecules could make big waves. J Immunol. 2019;202:11-9. https://doi.org/10.4049/jimmunol.1800991.

27. Chen Y, de Bruyn KC, Kirchmair J. Data resources for the computer-guided discovery of bioactive natural products. J Chem Inf Model. 2017;57:2099_ 111. https://doi.org/10.1021/acs.jcim.7b00341.

28. Li T, Fan J, Wang B, Traugh N, Chen Q, Liu JS, et al. TIMER: a web server for comprehensive analysis of tumor-infiltrating immune cells. Cancer Res. 2017; 77:e108-e10. https://doi.org/10.1158/0008-5472.can-17-0307.

29. Rhodes DR, Kalyana-Sundaram S, Mahavisno V, Varambally R, Yu J, Briggs BB, et al. Oncomine 3.0: genes, pathways, and networks in a collection of 18,000 cancer gene expression profiles. Neoplasia. 2007;9:166-80. https://doi.org/10.1593/neo.07112.

30. Zhai W, Zhou X, Du J, Gao Y. In vitro assay for the development of small molecule inhibitors targeting PD-1/PD-L1. Methods in Enzymology Academic Press; 2019

31. Luan $Y$, Chai D, Peng J, Ma S, Wang M, Ma H, et al. A fully human monoclonal antibody targeting PD-L1 with potent anti-tumor activity. Int Immunopharmacol. 2016;31:248-56. https://doi.org/10.1016/j.intimp.2015.12.039.

32. Liang Z, Tian Y, Cai W, Weng Z, Li Y, Zhang H, et al. High-affinity human PDL1 variants attenuate the suppression of T cell activation. Oncotarget. 2017; 8:88360-75. https://doi.org/10.18632/oncotarget.21729.

33. Xu Y, Cui G, Jiang Z, Li N, Zhang X. Survival analysis with regard to PD-L1 and CD155 expression in human small cell lung cancer and a comparison with associated receptors. Oncol Lett. 2019;17:2960-8. https://doi.org/10. 3892/ol.2019.9910

34. Manieri NA, Chiang EY, Grogan JL. TIGIT: a key inhibitor of the Cancer immunity cycle. Trends Immunol. 2017;38:20-8. https://doi.org/10.1016/j.it. 2016.10.002

35. Bowers JR, Readler JM, Sharma P, Excoffon K. Poliovirus receptor: more than a simple viral receptor. Virus Res. 2017;242:1-6. https://doi.org/10.1016/j. virusres.2017.09.001.

36. Peng J, Xiao $Y, L i$ W, Yang $Q$, Tan $L$, Jia $Y$, et al. Photosensitizer micelles together with IDO inhibitor enhance cancer photothermal therapy and immunotherapy. Adv Sci (Weinh). 2018;5:1700891. https://doi.org/10.1002/ advs.201700891.

37. Krashin E, Piekielko-Witkowska A, Ellis M, Ashur-Fabian O. Thyroid hormones and cancer: a comprehensive review of preclinical and clinical studies. Front Endocrinol (Lausanne). 2019;10:59. https://doi.org/10.3389/fendo.2019.00059.

38. Funazo TY, Nomizo T, Ozasa H, Tsuji T, Yasuda Y, Yoshida H, et al. Clinical impact of low serum free T4 in patients with non-small cell lung cancer treated with nivolumab. Sci Rep. 2019;9:17085. https://doi.org/10.1038/ s41598-019-53327-7.

39. Ma B, Duan X, Zhou Q, Liu J, Yang X, Zhang D, et al. Use of aspirin in the prevention of colorectal cancer through TIGIT-CD155 pathway. J Cell Mol Med. 2019;23:4514-22. https://doi.org/10.1111/jcmm.14332.

40. Fang L, Zhao F, Iwanowycz S, Wang J, Yin S, Wang Y, et al. Anticancer activity of emodin is associated with downregulation of CD155. Int Immunopharmacol. 2019;75:105763. https://doi.org/10.1016/j.intimp.2019. 105763.

\section{Publisher's Note}

Springer Nature remains neutral with regard to jurisdictional claims in published maps and institutional affiliations.
Ready to submit your research? Choose BMC and benefit from:

- fast, convenient online submission

- thorough peer review by experienced researchers in your field

- rapid publication on acceptance

- support for research data, including large and complex data types

- gold Open Access which fosters wider collaboration and increased citations

- maximum visibility for your research: over $100 \mathrm{M}$ website views per year

At BMC, research is always in progress.

Learn more biomedcentral.com/submissions 